CHROM. 6320.

\title{
Identification of cannabicyclol with a pentyl or propyl side-chain by means of combined gas chromatography-mass spectrometry
}

Cannabicyclol occurs only in minor concentrations in natural marihuana and hashish samples. The compound was first isolated by KORTE AND SIEPER'. Later, GAONI AND MIFCHOULAM ${ }^{2}$ and CIAUSSEN at al. ${ }^{3}$ isolated the compound and elucidated its molecular structure. The structure was confirmed by the synthesis of the compound by CROMBIE at al.4. GAONi AN1) MECHOULAM were also the first to determine the retention time in gas chromatograply $(\mathrm{GC})$ on a column of $2 \% \mathrm{OV}$-I7. In our experiments, we found that cannabicyclol was the first compound to be eluted from the OV-I7 column with a molecular weight of 3I4. The compound could be separated from the other well known lashish constituents by GC, and by combining GC and mass spectrometry (MS) it was simple to obtain the mass spectrum of cannabicyclol. Although the fragmentation pattern of the cyclol is not well understood, the mass spectrum can be distinguished clearly from the mass spectra of other cannabinoids, for example, cannabichromene, cannabicliol, 1,6 - and 1,2-tetrahydrocannabinol, all of which have a molecular weight of $3{ }^{4} 4$ and fragnents $m / e 299,27 I, 258,246,243$ and 231 in common.

It is known that the main constituents with a pentyl sicle-chain are accompanied by their homologues bearing a propyl and a methyl side-chain ${ }^{5-10}$. It might therefore be expected that cannabicyclols, with propyl and methyl side-chains, also exist. The detection of these compounds depends largely upon the availability of a haslish or marihuana sample in which the $C_{3}$ and $C_{1}$ compounds are present in such a concentration that they can be detected and identified.

\section{Matcrials and mothods}

An etlicr extract of a sample of Congo marihuana was injected into the GLC HP 402 and into the GC-MS LKB 9000 instruments. In each instance, the columns were filled with $3 \%$ OV-I7 on Gas-Chrom Q, 60-80 mesh. The carrier gas was helium at a flow-rate of $20 \mathrm{ml} / \mathrm{min}$; temperature of the oven $I 80^{\circ}$, of the separator $240^{\circ}$, and of the ion source $290^{\circ}$; accelerating potential $3.5 \mathrm{kV}$; trap current $60 \mu \mathrm{A}$; and the electron energies $20, I 8, I 6, I 4, I 2$ and $10 \mathrm{eV}$ during the elution of a peak. The spectra obtained were normalized and the relative abundances of a particular mass fragment were plotted against the electron energy used ${ }^{\mathrm{B}-10}$. The propyl side-chain is indicated with $C_{3}$, the methyl side-chain with $C_{1}$ and the pentyl side-chain with $C_{5}$. Retention times are measured in centimetres; the fictive retention is calculated with I-2-THC-C ${ }_{5}^{*}$ as the reference compound with a fictive retention of roo (ref. II).

\section{Results}

Mass spectrometry. The mass spectrum of cannabicyclol- $\mathrm{C}_{5}$ obtained from the marihuana samples was identical with that of the compound isolated by GAONI AND MECHOULAM ${ }^{2}$. The mass spectra at $20 \mathrm{eV}$ of cannabicyclol with a pentyl $\left(\mathrm{C}_{5}\right)$ and propyl $\left(\mathrm{C}_{3}\right)$ side-chain are given in Table $\mathrm{I}$. omitted).

$\Delta \mathrm{I}, 2-\mathrm{THC}=1,2$-tetrahydrocannabinol; monoterpenoid numbering (in this paper $\Delta$ is 
TABLE I

MASS SPECTRA OF CANNABICYCLOLS AT $20 \mathrm{cV}$

\begin{tabular}{lcc}
\hline $\begin{array}{l}\text { Mass fragment } \\
\text { m/e }\end{array}$ & \multicolumn{2}{c}{ Relative abundance $(\%)$} \\
\cline { 2 - 3 } & Caninabicyclol-C & Cannabicyclol-C \\
\hline 314 & 33 & \\
299 & 7.5 & 20 \\
286 & 5 & 6 \\
$27 \mathrm{r}$ & 7 & \\
258 & 3 & \\
246 & 5 & 2 \\
243 & 100 & 2 \\
$23 \mathrm{r}$ & & 100 \\
230 & & \\
218 & 5 & \\
203 & & \\
174 & & \\
\hline
\end{tabular}
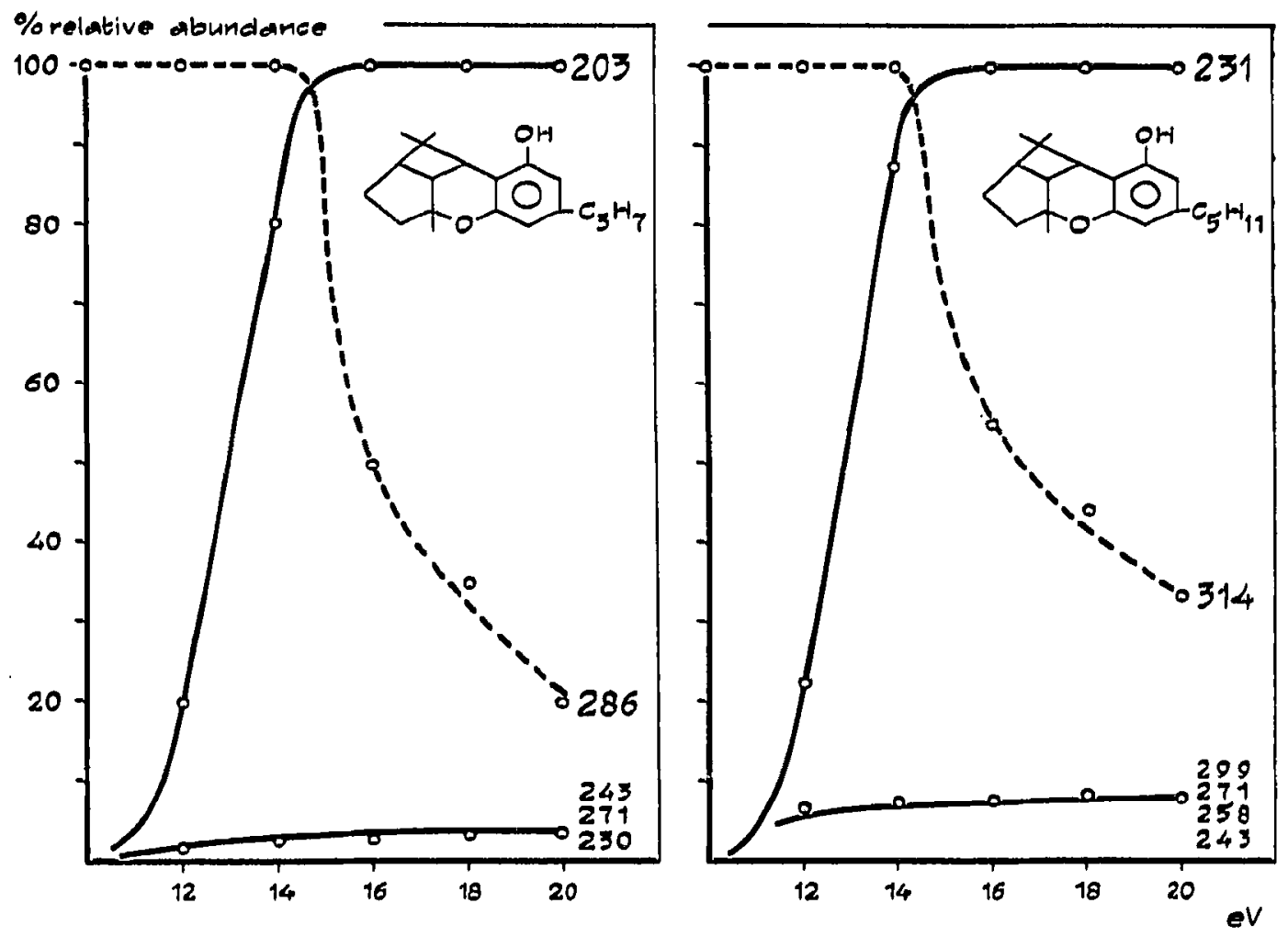

Fig. I. Relative abundance of tho mass fragments plotted against the oloctron encrgy used.

When the relative abundances of the mass fragments are plotted against the electron energy used, as shown in Fig. $I$, the graphs have the same shape but the corresponding mass fragments have a constant difference of 28 , which, by analogy 
with THC-C ${ }_{3}, \mathrm{CBD}-\mathrm{C}_{3}{ }^{*}$ and $\mathrm{CBN}-\mathrm{C}_{3}{ }^{* *}$ and other compounds that have structural differences only in the side-chain (II), can be explained only by differences in the side-chain ${ }^{8-10,12}$. Also, the "crossing points" at $\mathrm{I}_{4} \mathrm{eV}$ of the line of $m / c$ 3I 4 with that of $m / v 23 \mathrm{I}$, and of $m / v 286$ with $m / v 203$, provides further evidence that apart from the side-chains, the molccular structures are identical ${ }^{10}$. For instance, the crossing point of the lines of the same fragments $m / e$ of camnabichromene- $C_{5}$ and $-C_{3}$ is at Io $\mathrm{eV}$.

Cannabicyclol- $\mathrm{C}_{5}$ can also be distinguished from cannabichromene- $\mathrm{C}_{5}, a . g .$, by the presence of the fragments $m / e: 299,271,258$ and 243 in equal relative abundances (6-8\%). The latter fragments are not present in cannabichromene- $C_{5}$. The same observation holds for the presence of the mass fragments $\mathrm{m} / \mathrm{e} 27 \mathrm{I}, 243,230$ and $2 \mathrm{IS}$ in cannabicyclol- $\mathrm{C}_{3}$, their being absent in cannabichromene- $\mathrm{C}_{3}$.

Gas chromatography. Gas chromatography provides some other evidence for the existence of cannabicyclol- $\mathrm{C}_{3}$. As was observed earlier, the ratio of the retention times of the cannabinoid homologues, beating a methyl, a propyl and a pentyl side-chain, is constant and almost inclependent of the camnabinoid and instrumental settings ${ }^{10,11,13}$.

TABLIE II

WISLATVE RE'LENTION TIMTSS

\begin{tabular}{|c|c|c|c|}
\hline Compolend & $\begin{array}{l}\text { Rotcution } \\
\text { (cm) }\end{array}$ & $\begin{array}{l}\text { Fictive } \\
\text { vetentions }\end{array}$ & $\begin{array}{l}\text { Relative } \\
\text { retcution time }\end{array}$ \\
\hline Cinnabicyclol- $\mathrm{C}_{3}$ & +.6 & $5 \cdot 4 \cdot 3$ & $\mathrm{I} .00$ \\
\hline Citnnabicyclol-C. & 9.8 & 30.0 & 2.09 \\
\hline $\mathrm{I}, 2-\mathrm{IIIC} \mathrm{C}_{3}$ & - & 50.0 & I.OO \\
\hline I, 2-IHC-C & 32.5 & I00.0 & 2.00 \\
\hline $\mathrm{CBN}-\mathrm{C}_{3}$ & - & 60.0 & r.oo \\
\hline $\mathrm{CBN}-\mathrm{C}_{5}$ & 一 & 126.0 & 2.10 \\
\hline
\end{tabular}

"Gas chromatogram of Congo marihuana on $3 \%$ OV-r7 at $180^{\circ}$.

b See ref. i I.

From Table II, it can be clerived that the ratio of the retention time of cannabicyclol$\mathrm{C}_{3}$ to that of cannabicyclol- $\mathrm{C}_{5}$ fits well with the results obtained for the known structures $\mathrm{THC}^{-\mathrm{C}_{3}} / \mathrm{C}_{5}, \mathrm{CBN}-\mathrm{C}_{3} / \mathrm{C}_{5}$, etc.

The authors wish to thank Prof. R. MEchouLAM for kindly supplying cannabicyclol- $\mathrm{C}_{5}$.

This work was supported in part by grants from the Netherlands Organization

$" \mathrm{CBD}=$ cannabidiol.

- $\mathrm{CBN}=$ cannabinol. 
for the Advancement of Pure Research (ZWO) and from the Prevention Fund, Ministry of Health.

Department of Pharmacology,

T. B. VRE1:

University of Nijmegen,

Nijunegen (The Netherlands)

D. D. BREMMER

C. A. M. VAN GINNEKRN

J. M. van Rossum

I F. FORTE AND H. SIEper, $f$. Chromatogr, , 3 ( r96.f) 9o.

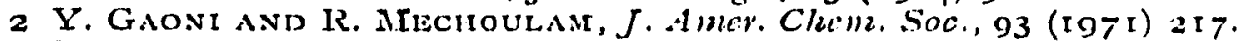

3 U. Clausen, F, von Spulak and F. Korte, Tetrahedron, $2+$ (tg68) $102 \mathrm{r}$.

4 L. Crombie, R. Ponsford, A. Shani, B. Fignitinsky asp IR. Mfrehoulan, Tetrahedron Lett., (1968) $577 \mathrm{I}$.

5 L. D. VOLLNieR, D. BIENiEK AND F. ISORTE, Tetvahedron Lctt., (1969) It5.

6 IE. W. GiLL, J. Chem. Soc., $802(\mathrm{r} 97 \mathrm{r}) 579$.

7 F. W. H. M. Mirkis, Pharm. Werkbl., Io6 (I97I) 69.

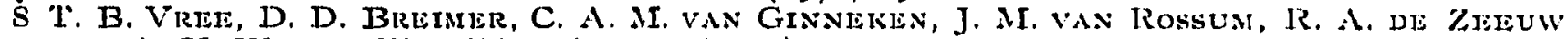
AND A. H. WITte, Clin, Chim. Acla, 34 (I97I) 365.

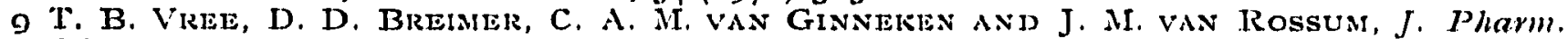
Pharmacol., $2+$ (1972) 7 .

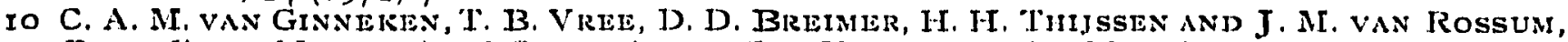
Procedings of International Sympositem on Gas Chromatography-hass Spectrometry, Jilba, Italy, I972. Tamburini press, Milan.

I I. B. Vkee, D, D. Brelmer, C. A. M. van Ginneken and J. MI. VAN Rossum, J. Chromatogr, $7+(1972) 209$.

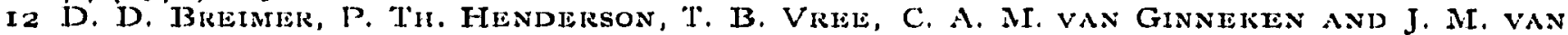
IRossum, Procedings of Intemational Symposimm on Gas Chromatography-. Tass Spictroncty, Jlba, llaly, I972, "lamburini press, Milan.

13 T. B. VReE, D. D. Breimer, C. A. M. van Ginseres, J. M. van lRossum et al., Chem. We $8(\mathrm{r} 972) \mathrm{H} r$.

Received August 25th, I972 